\title{
ESTUDO COMPARATIVO ENTRE OS COMPLEXOS DE BARRO ALTO E DO TOCANTINS, GOIAS
}

\author{
ALMIR NEVES DE FIGUEIREDO* \\ JORGE MOTTA* \\ VÁLTER JOSÉ MARQUES*
}

\begin{abstract}
The two largest gabbro-peridotite-anorthositic Complexes presently recognized in Brazil, the Barro Alto and the Tocantins Complexes, outcrop in the central region of the Goias State. They are believed to be Early Precambrian in age. The two complexes contain the same suite of rocks and have similar chemical, textural and mineralogical aspects. Stratiform and alpine features are present in both complexes.
\end{abstract}

HISTÓRICo Exceção feita aos trabalhos de caráter específico, sobre cada um deles, os Complexos de Barro Alto e do Tocantins, juntamente com outros de porte semelhante ou menores, receberam já, por parte de alguns autores, um tratamento mais amplo, regional, no qual aparecem implícita e automaticamente, termos de comparação entre eles. Destacam-se, desses autores, Almeida (1967), Angeiras (1968), Barbosa et alii (1969), da Costa e Angeiras (1970), Thayer (1970), Fleisher e Routhier (1970) e Berbert (1970).

Da mesma forma comparativos, porém em termos mais restritos, são dignos de nota os estudos de White (1970), Lindenmayer e Lindenmayer (1971) e Nilson (1971), o primeiro no campo petrográfico e os restantes no econômico.

Almeida (op. cit.) menciona que, como manifestação precoce do ciclo geossinclinal relacionàda com o Grupo Araxá - ambiente eugeossinclinal - formou-se, através do magmatismo básico e ultrabásico de caráter alpino, uma dupla faixa de gabros, piroxenitos e peridotitos serpentinizados, cuja idade parece próxima de $1100 \mathrm{~m} . \mathrm{a}$. Segundo ele, as condiçzes eugeossinclinais de sedimentação e ascenção de grandes volumes de magma básico e ultrabásico - o serpentine belt goiano - resultaram de um importante fraturamento da crosta, ocorrido a partir de 1200 m.a. (Pré-Cambriano Superior), no interior de Goiás, o qual separou as plataformas de São Francisco e Guaporé.

Angeiras (op. cit.) refere-se à presença de várias dezenas de complexos ultrabásicos com gabros associados, intrusivos no Grupo Araxá, constituindo, indubitavelmente, uma faixa de serpentinitos originada pelo magmatismo ofiolítico precoce (magmatismo inicial de Stille) da tecto-orogênese que afetou o eugeossinclíneo Araxá. Após situá-los geotectonicamente e apresentar suas características gerais, até então conhecidas, esse autor, baseando-se em trabalhos de Benson e Thayer, considera que os maciços ultrabásicos da região central de Goiás apresentam uma perfeita analogia com o chamado tipo alpino. Além disso, trata no tópico final, dos depósitos minerais associados, antevendo imensas possibilidades para a região central de Goiás.

Barbosa et alii (op. cit.), considerando as idades aparentes de cerca de 900 m.a., entáo determinadas pelo Instituto de Geocronologia da Universidade de São Paulo, em rochas consideradas pertencentes aos maciços de Cana Brava, Niquelândia e Barro Alto, aventam a hipótese de que suas rochas seriam, no mínimo, contemporâneas ao último metamorfismo sofrido pelas rochas do Grupo Araxá. Descortinam a possibilidade de elas serem mais antigas e "rejuvenescidas" ou, ainda, intrusivas em rochas do Pré-Cambriano indiferenciado, compondo, ambas, a superficie de sedimentação Araxá. Entretanto, sem dados mais concretos que os façam assumir tais assertivas, admitem que, no início da sedimentação

*Cia. de Pesquisas de Recursos Minerais - CPRM - Agência Goiânia, Goiannia, Goiás 
Araxá, houve a erupção de um vulcanismo básico e ultrabásico (anfibolitos e serpentinitos) e, ao fim do período de deformação e metamorfismo, aconteceram intrusões básicas e ultrabásicas (gabros, noritos, piroxenitos e peridotitos); os primeiros, basitos e ultrabasitos, correspondem à fase (1) da seqüência magmática de Stille e os últimos, à fase (3c). Destarte, acreditam ser ainda prematura a conclusão de que a zona de ultrabasitos serpentinizados que se estende do maciço de Cana Brava ao de Pontalina, correspondem a uma cinta (faixa) ofiolítica. Outrossim, apresentam os resultados de seus estudos petrográficos, estruturais e econômicos, sobre cada um dos referidos maciços.

Da Costa e Angeiras (op. cit.), reconhecendo a presença de outros corpos básicos-ultrabásicos em Goiás, à semelhança do Complexo do Tocantins, situam-nos, ainda com base em dados disponíveis de determinaçóes de idades aparentes de algumas de suas rochas, como prováveis representantes do magmatismo inicial do eugeossinclíneo Araxá. Registram a possibilidade de o Complexo do Tocantins vir a enquadrar-se no tipo "pseudo-estratiforme".

Thayer (op. cit.) confirma o reconhecimento de Almeida, no que se refere à presença, em Goiás, de um cinturão peridotítico alpino, representado igualmente quer pelos grandes corpos básico-ultrabásicos quer pelos pequenos corpos peridotíticos, acreditando-os co-magmáticos e de idades similares. Ressalta as diversas feições análogas exibidas pelos três grandes complexos por ele visitados - Tocantins, Barro Alto e Cana Brava - e aprofunda-se em considerações sobre seus potenciais econômicos maiores.

Fleischer e Routhier (op. cit.) enquadram os grandes "aparelhos" básico-ultrabásicos de Goiás na categoria de "maciços diferenciados" e, com base nas principais características petrográficas e estruturais, observadas no Complexo do Tocantins, estabelecem comparaçð̋es entre este e o Complexo de Stillwater (Montana, EUA). São os primeiros a registrar como "abuso de linguagem" a caracterização dos aparelhos básicos de Goiás sob a terminologia de ofiolitos.

Os trabalhos de Berbert, White, Lindenmayer e Lindenmayer e Nilson ( $o p$. cit.), configuram, em linhas gerais, toda uma corrente de pensamentos esboçada por geólogos do DNPM e CPRM que trabalharam nas regiões de Niquelândia e Goianésia-Barro Alto, e expostá nos relatórios finais dos projetos de mesmo nomes, executados pela GPRM; através de contrato firmado com o DNPM.

INTRODUÇÃo Durante os últimos cinco anos, os autores participaram, respectivamente, das equipes que mapearam os dois maiores conjuntos gabro-peridotitomanortosíticos até agora identificados no Brasil: os Complexos de Barro Alto e do Tocantins. Situam-se eles na região centro-sul do Estado de Goiás, entre os paralelos $14^{\circ} 00^{\prime}$ e $15^{\circ} 30^{\prime} \mathrm{S}$ e os meridianos $48^{\circ} 15^{\prime}$ e $49^{\circ} 15^{\prime}$ W.G.

O Complexo do Tocantins, designação proposta por Pecora e Barbosa (1944) para descrever o conjunto de rochas básicas e ultrabásicas, localizado no Município de Niquelândia, antiga São José do Tocantins, é, dentre os doịs, o mais conhecido e estudado. Já em 1942, Barbosa o caracterizara como exibindo formato de uma oval, com a parte achatada voltada para o sul. Posteriormente, Lindenmayer (1970) estabelece a figura geométrica de uma lente biconvexa na interpretação de seu possível formato. Remonta ao trabalho de Pecora e Barbosa (op. cit.) a tendência, progressivamente apurada por Motta et alii (1970), Lindenmayer (op. cit.) e Motta et alii (1972), de subdividi-lo em Zonas ou Faixas, de acordo com seus respectivos tipos litológicos.

O Complexo de Barro Alto, com registros apenas superficiais na literatura geológica nacional, foi inicialmente descrito por Thayer (1970) como aflorante, sob a forma de um bumerangue, ou, segundo Baeta, Figueiredo et alii (1972), sob o formato de um arco de 
$156 \mathrm{~km}$ de comprimento, apresentando larguras máxima e mínima de 22 e $8 \mathrm{~km}$. A Seqüência Oriental desse arco, cuja concavidade aponta para NW, estende-se no rumo N40E, das proximidades setentrionais de Goianésia, às margens do Rio das Almas. Tão somente para esta, denominada Seqüência Oriental Diferenciada por Baeta, Figueiredo et alii (op. cit.), foi possível estabelecer uma subdivisão em Zonas, à semelhança do caracterizado para o Complexo do Tocantins. Sua Seqüência Ocidental, que se prolonga rumo EW, das proximidades setentrionais de Goianésia às circunvizinhanças de Rubiataba, é considerada, com base em determinados parâmetros químicos, petrográficos e estruturais, como representativa de rochas do cráton do Brasil Gentral, originalmente metamorfizadas à fácies granulítica.

O objetivo deste trabalho é chamar a atenção para as analogias observadas em tais complexos e, em contrapartida, justificar a impossibilidade de situá-los dentro dos tipos de classificações propostas e defendidas na literatura geológica mundial para caracterizar complexos gabro-peridotíticos (Thayer, 1960), haja visto que tais complexos apresentam similaridades, tanto em relação aos considerados alpinos (particularmente nas suas porções ultrabásicas), quanto aos denominados estratiformes (notadamente em suas Zonas superiores). Fortalece-se, dessa maneira, a possibilidade, há muito pressentida por geólogos que os visitaram, como Iran Machado (com. oral, 1969) e Thayer (com. oral, 1972), ou que trabalharam em suas áreas, de que os Complexos do Tocantins e Barro Alto sejam os representantes de um novo tipo, funcionando o primeiro, por suas características mais completas e melhor estudadas, como paradigma.

Divisão em Zonas A predominância de determinados tipos litológicos principais, estabelecidos com base na petrografia convencional, foi o artificio utilizado para a divisão em Zonas, dos Complexos de Barro Alto e do Tocantins.

O termo Zona, a despeito das conotações que se lhe tem procurado dar, veio a ser o escolhido, e não deve ser interpretado no sensu stricto de Wager e Brown (1968) significando determinada espessura de rochas acamadadas (layered rocks) desenvolvidas enquanto determinado mineral cumulado ou assembléia de minerais cumulados esteve se formando, mas sim, significando uma unidade informal de rocha estratigráfica, mapeável, de uma intrusão, caracterizada por homogeneidade litológica ou distintas feiçôes litológicas.

A Fig. 1 registra uma tentativa de correlação entre as respectivas Zonas desses dois grandes complexos goianos, através de suas seções tipo idealizadas. Note-se, todavia, que apenas em determinados perfis é possível descrever-se a seqüência completa de rochas representadas em tais seções. Isso se deve principalmente ao fato de a grande maioria de suas zonas particularizar-se por variações laterais e longitudinais em espessuras, algumas das quais, verdadeiramente inexistentes em determinados locais, como é o caso da Zona Anortosítica de Barro Alto, e da Sub-zona Peridotito-piroxenítica do Tocantins, năo representadas nos extremos setentrionais dos respectivos complexos. Ademais, as formas originais de tais intrusões foram muito possivelmente alteradas pelos sucessivos eventos tectônicos a que foram submetidas.

Zonas Basais GENERALIDADES As relações de contato, entre as respectivas Zonas Basais das intrusões de Barro Alto e Niquelândia e suas principais encaixantes comuns do Complexo Basal e Grupo Araxá, enquadram-se quase exclusivamente no tipo falhado, e a única exceção digna de registro foi observada nas proximidades do extremo setentrional do Complexo de Barro Alto, onde se constataram interdigitações locais de gabros anfibolitizados com o produto de alteração de rochas que, por exibirem aspecto xistoso, foram provisoriamente interpretadas como pertencentes ao Grupo Araxá.

Seus contatos interiores com ultrabásicas diferem significativamente para cada com- 


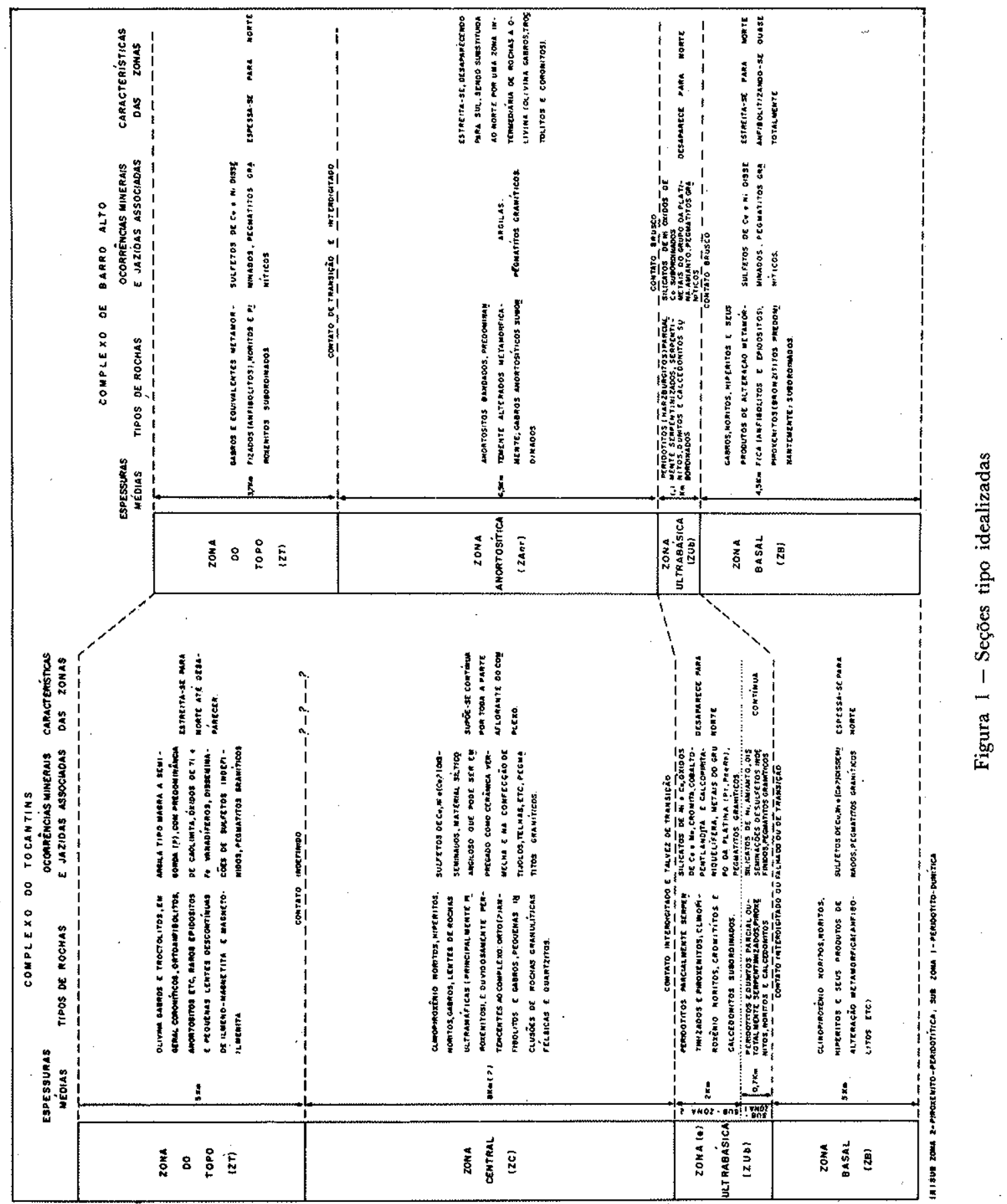


plexo. Em Barro Alto, eles são vistos, a priori, invariavelmente bruscos, quando não falhados; enquanto que, no Tocantins, o mais característico é, ao que tudo o indica, definido por uma série de intercalações de termos básicos e ultrabásicos, configurando um contato interdigitado. Além desse, ocorrem ali, local e subordinadamente, mais dois tipos: o falhado e o de transição, este último definido pela presença de uma rocha gábrica com olivina.

PETROGRAFIA Essencialmente gábricas em composição, metamorficamente alteradas ou não, as rochas de suas Zonas Basais exibem, macroscopicamente, uma orientação planar, fruto da interação milimétrica de leitos máficos e félsicos.

Microscopicamente, a textura é quase sempre granoblástica ou granular hipidiomórfica. De granulometria fina, apresentam o plagioclásio básico (labradorita-bytownita), ortopiroxênio e clinopiroxênio como seus principais minerais essenciais. Acessórios freqüentes são a uralita, espinélio, quartzo, biotita e sulfetos. Grafita é um acessório incomum e melhor observado em gabros basais do Complexo de Barro Alto.

De acordo com as proporções relativas entre seus três principais minerais essenciais, tais rochas gábricas variam em composição de noritos, quando é amplo o predomínio do ortopiroxênio sobre o clino, a hiperitos, quando as proporções relativas entre esses dois inossilicatos mais ou menos se equivalem. Para o topo de tais Zonas, observa-se o apare* cimento, local e subordinado, de termos piroxeníticos, principalmente bronzititos.

$\mathrm{O}$ ortopiroxênio é o hiperstênio ou, mais freqüentemente, a bronzita. $\mathrm{O}$ clinopiroxênio, por motivos técnicos, não teve determinada sua composição em termos estatisticamente satisfatórios, porém algumas medidas de seus ângulos ópticos revelaram tratar-se de membro da série diopsídio-augita.

Uma característica igualmente comum aos ortopiroxênios de Barro Alto e do Tocantins, é o desenvolvimento de lamelas de clinopiroxênio paralelas à face (100) ou (001).

A despeito da ausência de suficientes análises químicas e de estudos petrográficos mais detalhados, fato que limita as conclusões aqui registradas, os produtos de alteração metamórfica de gabros basais de ambos os complexos revelaram a existência de, pelo menos, dois tipos de anfibólios. $O$ primeiro deles, uma hornblenda marrom, é observado em rochas essencialmente compostas desse mineral, plagioclásio, epidoto, talco, granada e relictos de piroxênio. Correspondem, talvez, à fácies metamórfica regional, correlacionável ao metamorfismo Araxá. O segundo, exibido pelas rochas basicamente compostas de tremolita-actinolita, clorita, talco e carbonato, restringe-se a zonas mais intensa e tectonicamente movimentadas.

Zonas UItrabásicas GENERALIDADES Face às características peculiares, e implicações delas derivadas, as relações de contato entre as Zonas Ultrabásicas dos Complexos do Tocantins e Barro Alto, com suas respectivas e distintas zonas sobrejacentes, necessitam um estudo em separado.

Em Barro Alto, os contatos entre Zona Ultrabásica e Zona Anortosítica, são definitivamente bruscos, embora não definidamente falhados, e acham-se mascarados por ampla e espessa faixa de material argiloso misturado a fragmentos e blocos de rochas derivadas das elevações a seu redor. A exaustiva busca no campo da caracterização de mais de um tipo de contato resultou tão somente na comprovação quase categórica de ausência de contatos interdigitados e/ou transicionais.

No Tocantins, as relações de contato entre a Zona Ultrabásica e a Zona Central assemelham-se, ao que tudo o indica, àquelas entre suas Zona Ultrabásica e Zona Basal. $\mathrm{Ali}$, foram descritos contatos do tipo interdigitado e igualmente transicional, restando a possibilidade, a ser futuramente estudada, de que o contato mais representativo seja o do tipo composto, qual seja, ao mesmo tempo interdigitado e transicional. 
A predominância, no que respeita ao Complexo do Tocantins, de determinadas lentes e/ou camadas mapeáveis, de litologia distinta, permitiu o artificio de subdividir-se sua Zona Ultrabásica em: Subzona Peridotito-dunítica e Subzona Peridotito-piroxenítica, nessa ordem, da base para o topo ou de leste para oeste.

A Zona Ultrabásica do Complexo de Barro Alto, a despeito de apresentar, exceção feita aos cromititos e rochas gábricas, todos os tipos petrográficos exibidos pela correspondente Zona Ultrabásica do Tocantins, não comporta, no estágio atual de conhecimentos, subdivisões.

PETROGRAFIA Peridotitos Representados pelas rochas de coloração negra a verde-escura, quando frescas, a amareladas, quando alteradas, exibem granulometria fina a média e compõem-se microscopicamente de olivina, orto e clinopiroxênio, e serpentina. Seus principais acessórios são: carbonatos, magnetita, talco, eddingsita e pirrotita. Alguma grafita, foi observada unicamente em exemplares de Barro Alto.

Quer em Barro Alto, quer no Tocantins, revelaram tratar-se de harzburgitos, ocorrendo, neste último, quantidades subordinadas de lherzolitos. Estudos ópticos em olivinas dessas rochas revelaram, em termos de percentagens de forsterita, composições em torno de $\mathrm{Fo}_{85 \sim 97}$.

O grau de serpentinização exibido por tais rochas varia amplamente nos limites de 10 a $95 \%$ e registra-se, em ambos os complexos, uma progressiva diminuição na serpentinização em direção ao topo de suas Zonas Ultrabásicas. Estudos de imersão e difração de raios X definiram a lizardita como seu principal mineral de serpentina, verificando-se, a ela associadas, quantidades subordinadas de crisotila.

Estudos idênticos para os ortopiroxênios mostraram uma composição uniforme, em torno de $\mathrm{En}_{90}$, para os exemplares de ambos os complexos. O clinopiroxênio, de presença definida apenas para os exemplares do Tocantins, e mesmo ali, de abundância restrita, não veio a ser déterminado.

Dunitos Negros, quando frescos, adquirem tons amarelados ao se alterarem. De granulação média a fina, são mais freqüentes ao longo da Zona Ultrabásica do Tocantins, caracterizando uma das principais litologias de sua Subzona Inferior. Em Barro Alto, estranhamente, foram descritos quase que exclusivamente mais para o topo de sua Zona Ultrabásica, o que é dificilmente explicável na seqüência de um processo de diferenciação magmática normal.

Ao microscópio, têm, na olivina e na serpentina, seus principais constituintes e, como acessórios, espinélio cromífero, magnetita, talco, brucita e cromita, esta última reconhecida até o presente apenas em exemplares do Tocantins, o que não exclui, todavia, a possibilidade de vir a ser descrita em ultrabásicas de Barro Alto, reconhecidaménte carentes de maiores estudos petrográficos.

Piroxenitos De cores variegadas, mais comumente marrom a esverdeados, caracterizam-se por generalizada isotropia. Mineralogicamente compostos de ortopiroxênio (bronzita ou enstatita) e piroxênio (augita-diopsídio), de acordo com suas proporções relativas, foram configurados como bronzititos ou enstatolitos, quando ocorre o predomínio acentuado do orto que lhes empresta o nome, ou websteritos, quando a razão orto/clino é aproximadamente um.

À semelhança do observado nas rochas gábricas basais, os ortopiroxênios exibem freqüentes lamelas de clinopiroxênio paralelas ao plano (100) ou (001). A presença de kink bands sobretudo descritas em amostras do Tocantins, não é um fato incomum. 
Calcedonitos Como produtos secundários do intemperismo químico atuante sobre as rochas ultrabásicas, observa-se o desenvolvimento, ao longo de elevações, de calcedonitos, que preservam a topografia local e que serviram de apoio, particularmente no Tocantins, à formação dos vales em $\mathrm{U}$, portadores dos jazimentos de níquel silicatado.

Rochas gábricas e cromititos Lentes de rochas gábricas a bronzita e clinopiroxênio (diopsídio-augita), assim como lentes, a menos freqüentemente camadas de cromititos, descontínuas, irregulares em tamanho e tipicamente podiformes, foram observadas e estudadas tão somente ao longo da Zona Ultrabásica do Tocantins.

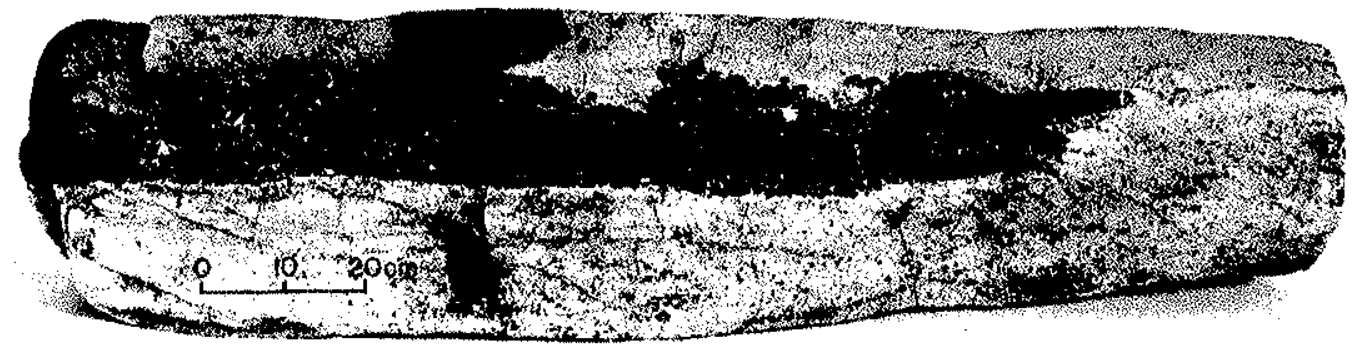

Foto 1 - Aspecto da cromita podiforme do Complexo do Tocantins. Note-se seu caráter lenticular e irregular

O contato entre tais rochas gábricas e ultrabásicas envolventes é brusco, necessitando-se, todavia, de estudos mineralogicos mais acurados para seu perfeito entendimento. Análises de imersão e difração de raios $\mathbf{X}$, desenvolvidas em umas poucas amostras de tais rochas, revelaram a seguinte composição: o plagioclásio é a bytownita, o ortopiroxênio é a bronzita, existindo dúvidas no que concerne ao clinopiroxênio, pois, enquanto White (op. cit.) identifica tais minerais como augitas típicas, Lindenmayer et alii (op. cit.) caracterizam-nos como diopsídios.

Um fato a ser registrado é a completa ausência, por toda a Zona Ultrabásica do Complexo de Barro Alto, de camadas, lentes e até mesmo fragmentos de cromititos. Ao término dos trabalhos de pesquisa para níquel, desenvolvidos na área pela Cia. Baminco S/A., Brocks (com. oral) registrou a presença de um único fragmento de cromita, de diâmetro inferior a cinco centímetros. Tal fato revela-se inexplicável, considerando-se a fonte magmática similar e, provavelmente, de composição idêntica, que deu origem a tais complexos (veja o item Quimismo adiante).

Zonas Anortosítica e Central GENERALIDADES As relações de contato entre a Zona Anortosítica e a Zona do Topo do Complexo de Barro Alto são tipicamente de transição, refletidas no campo pela passagem de rochas anortosíticas para gabros anortosíticos a, finalmente, gabros e seus produtos de alteração metamórfica - anfibolitos - através do progressivo enriquecimento em minerais máficos constituintes.

As texturas exibidas por tais anortositos são tanto ígneas ou primárias [estratificação cruzada, acamadamento gradacional, cumulus e dobras isoclinais (Fotos 2 e 3)], quanto metamórficas ou secundárias (desenvolvimento de hornblenda às expensas e piroxênios, etc.)

No que diz respeito ao Complexo do Tocantins, a presença de uma Sequiência de rochas granulíticas entre suas zonas Central e do Topo (Foto 4) mascarou completamente suas possíveis relaçoes de contato, as quais permanecem indefinidas no atual estágio de conhecimentos, A referida Seqüência Granulítica, originalmente definida por Lindenmayer (1970) e posteriormente ampliada em seus limites por Motta et alii (1972), é vista como 

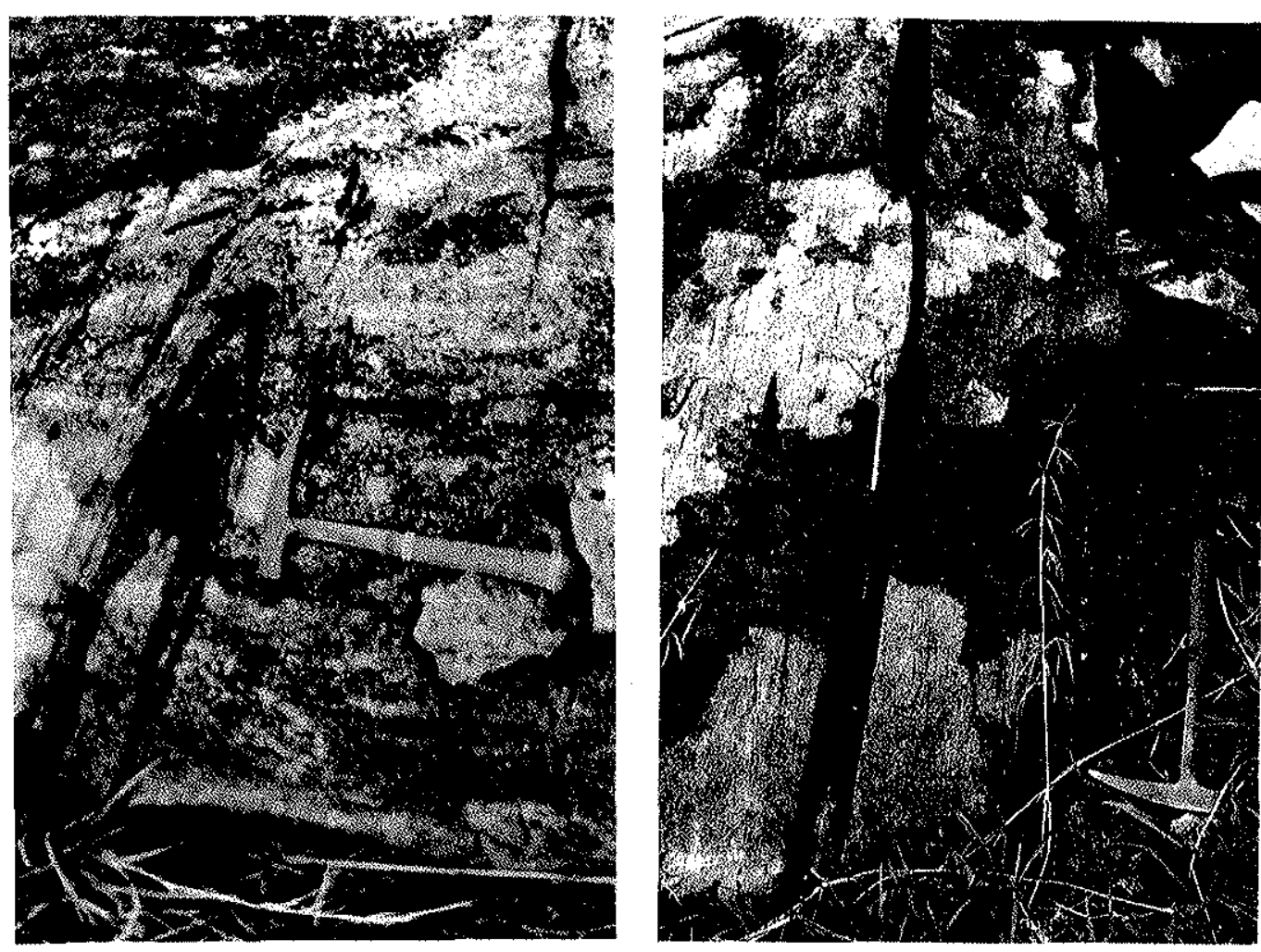

Fotos 2 e 3 - Belos exemplos de dobras isoclinais em anortositos a SW de Barro Alto

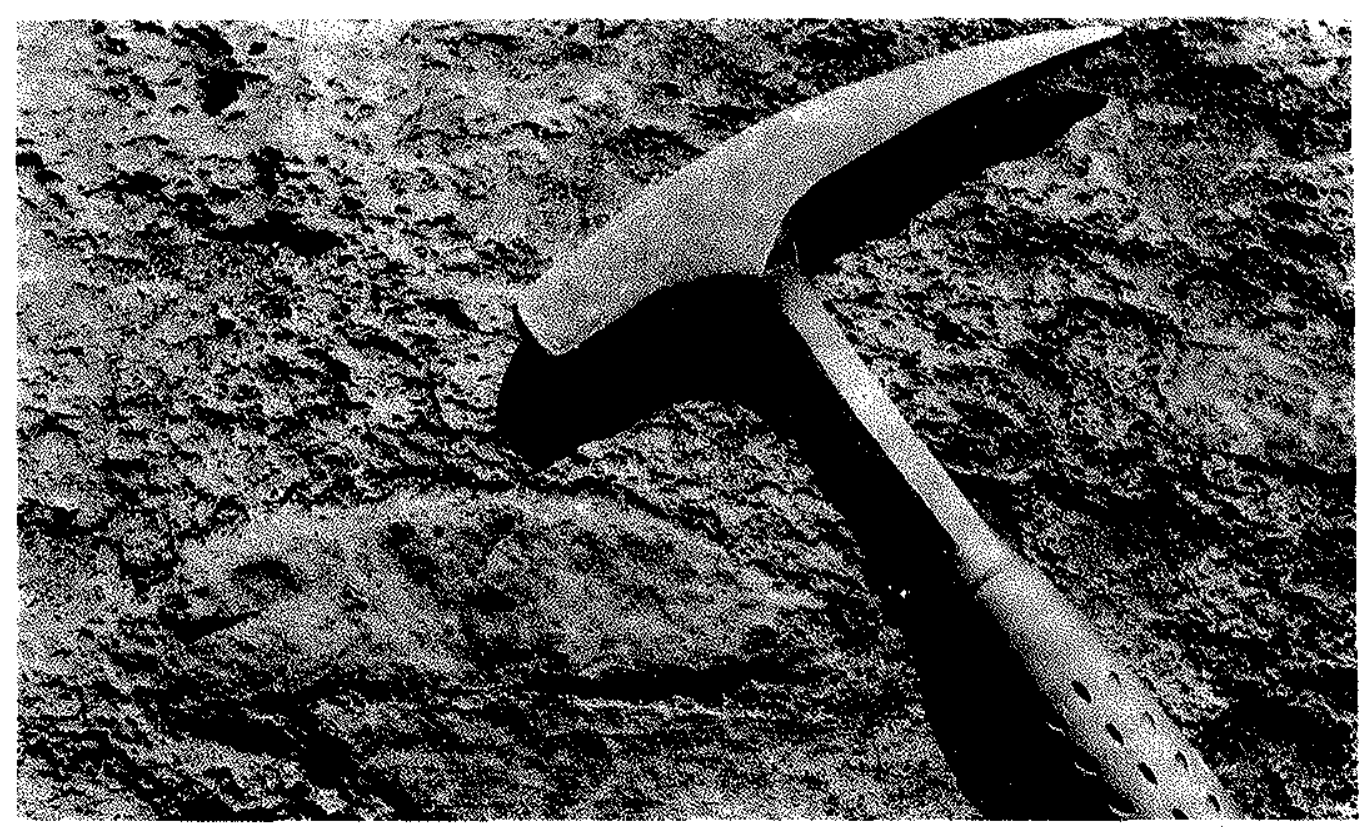

Foto 4 - Seqüuencia Granulítica do Complexo Basal. Pequenas lentes (fragmentos à semelhança de xenólitos) de composição gábrica; a rocha hospedeira é também de composição gábrica (granulito básico?) 
pertencente ao Complexo Basal (Almeida, 1967) e, conseqüentemente desvinculada geneticamente do Complexo do Tocantins.

Outrossim, os limites reais dessa Zona Central não foram plenamente estabelecidos, pressupondo-se que sua largura média aproximada de $8 \mathrm{~km}$ (Fig. 1) deva estar exagerada, pois nela se incluíram rochas de composição gábrica (granulitos básicos) possivelmente mais de perto associadas à Seqüência Granulítica. Note-se que, no extremo meridional do Tocantins, a presença de rochas granulíticas félsicas (camada-guia utilizada nos mapas do Projeto Niquelândia para separar parte da Seqüência Granulítica) parece diminuir bastante e até mesmo estar ausente. Conseqüentemente, a única relação possível de ser estudada seria entre rochas de composição básica, as quais poderiam:

a) pertencer todas à diferenciação do Complexo;

b) pertencer parte à Seqüência Granulítica (granulito básico) e parte à Zona do Topo do Complexo do Tocantins (gabros anfibolitizados, etc.).

Em se confirmando a primeira hipótese, as relações de contato entre Zona Central e Zona do Topo, enquadrar-se-iam, pelo menos ali, no tipo transicional.

Digna de registro é a presença, por quase toda a Seqüência Ocidental não-diferenciada do Complexo de Barro Alto, da totalidade dos principais tipos petrográficos apresentados pela Seqüência Granulítica.

PETROGRAFIA Os anortositos, que perfazem cerca de $90 \%$ das rochas da zona de mesmo nome do Complexo de Barro Alto, apresentam-se de coloração cinza-clara e branca, granulação média a média-grosseira, e caracterizam-se por exibir um nítido bandamento composicional (Foto 5). Pelo aumento em minerais máficos e conseqüente diminuição em plagioclásio, passam a gabros anortosíticos, configurados como os limites superiores dessa Zona.

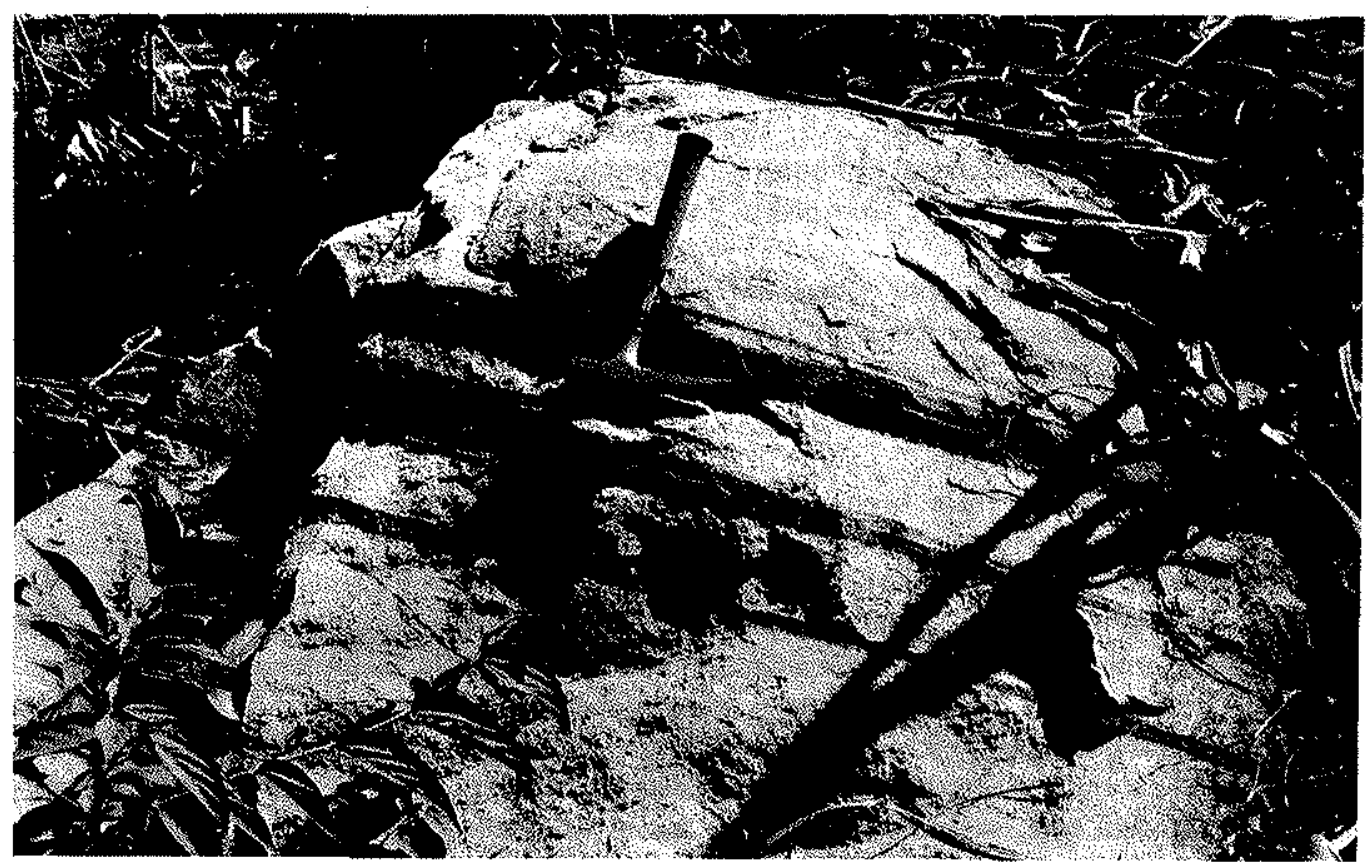

Foto 5 - Níveis máficos retilíneos de piroxênio e anfibólio em anortositos bandados 
Mineralogicamente, são compostos de plagioclásios que perfazem 70 a $100 \%$ da rocha, e variam, sistematicamente, da base para o topo da Zona, no intervalo $\mathrm{An}_{78-58}$. Hornblenda, granada e piroxênio (orto predominando sobre o clino) são, em proporções relativas extremamente variáveis, seus três outros minerais essenciais. Os dois primeiros, são nitidamente os produtos metamórficos da reação

$$
\text { plagioclásio + piroxênio } \rightarrow \text { hornblenda + granada + quartzo. }
$$

Acessórios mais freqüentes são quartzo, epidoto, coríndon, carbonatos e, mais raramente, grafita.

A despeito de o progressivo enriquecimento em cálcio exibido por seus plagioclásios sugerir uma estratificação crítica, ou criptic layering, de Wager e Deer (in Wager e Brown, 1968), fatores outros implicam na aceitação, sob reserva, de tal fenômeno, posto que, estudos de prováveis variações sistemáticas de piroxênios de tais rochas não foram desenvolvidos, face à conspícua alteração metamórfica por eles exibidas.

Petrograficamente, a Zona Central do Tocantins é composta, pelo menos no que se refere a sua porção mais oriental, de rochas de composição gábrica (noritos, hiperitos, gabros e gabros anortosíticos). São rochas de granulação fina a média, com predomínio desta última, e coloração cinza, cujas tonalidades médias revelam-se as mais representativas.

A mineralogia essencial é composta, de um modo geral, de plagioclásio básico, ortopiroxênio e clinopiroxênio, este último por vezes subordinado à forma lamelar. Como principais acessórios exibem: uralita, carbonato, granada, quartzo, saussurita, clorita e opacos (sulfetos). O ortopiroxênio é bronzita ou hiperstênio, que exibem freqüentes lamelas de clinopiroxênio. O clinopiroxênio veio a ser classificado por Lindenmayer (1970) como diopsídio.

Zonas do Topo GENERALIDADES Em ambos os complexos, tais zonas caracterizam-se por um sensível adelgaçamento em direção a suas extremidades norte.

Em Barro Alto, as relações de contato entre essa Zona e encaixantes comuns do Complexo Basal e Grupo Araxá revelam-se quase invariavelmente falhadas, exceção feita às proximidades de Capão Verde. Ali, obscura passagem de anfibolitos nitidamente derivados de rochas gábricas para anfibolitos intercalados a quartzitos, gnaisses e produtos xistosos de alteração (Araxá?, Complexo Basal?) não permitiu que tais relações fossem definidas.

No Tocantins, contatos por falhamentos foram comprovadamente observados apenas entre rochas anortosíticas da Zona do Topo e representantes do Conjunto Anfibolito-gnáissico do Complexo Basal. Situações similares às descritas anteriormente, para o Complexo de Barro Alto, impossibilitaram igualmente que, na sua maior parte, tais relações de contato viessem a ser definidas.

PETROGRAFIA Os tipos litológicos mais representativos dessas Zonas do Topo de ambos os Complexos são perfeitamente similares, a despeito de suas proporções relativas mostrarem-se amplamente variáveis. Generalizando, três são os principais minerais formadores de suas rochas: plagioclásio, piroxênio e olivina, este último de caráter subordinado aos exemplares de algumas regiões da Zona do Topo do Complexo de Barro Alto.

No Tocantins, sua Zona do Topo comporta subdivisão em áreas onde predominam os termos melanocráticos (noritos, gabros, piroxenitos e seus produtos de alteração metamórfica) e áreas onde o predomínio é de termos mais leucocráticos (anortositos e gabros anortosíticos), sem que, todavia, tais termos sejam mutuamente exclusivos. Obviamente, tal gama de rochas exibe coloração e granulometria variáveis, notando-se um certo predomínio da média. 
No que se refere a sua mineralogia essencial, observa-se que: o plagioclásio é quase predominantemente básico (labradorita-bytownita), exibindo freqüentes fenômenos de escapolitização e saussuritização; a hornblenda, de ocorrência progressivamente acentuada em direção às camadas do topo de ambos os complexos, exibe, nessa direção, mudança de pleocroísmo (de marrom para verde) e hábito (de prisma curto para alongado); a olivina não foi perfeitamente definida (forsterita-crisolita?), ocorrendo como cristais anédricos arredondados, quase invariavelmente orladas de coronas; o ortopiroxênio, principalmente bronzita ou, mais raramente, hiperstênio, caracteriza-se por exibir as já costumeiras lamelas de clinopiroxênio; o clinopiroxênio (diopsídio-diálaga), à semelhança dos orto, apresenta coronas de reação com o plagioclásio, formadas por anfibólios e granada.

Alguns dos principais acessórios de tais rochas são quartzo, granada, espinélio verde, pistacita-clinozoisita, antofilita-gedrita e opacos (sulfetos).

As texturas exibidas por tais rochas são, evidentemente, principalmente metamórficas; entretanto texturas magmáticas primárias, características de complexos estratiformes (Thayer, op. cit.) tais como cumulus, estratificação cruzada e aleitamento de plagioclásios acham-se preservadas em determinados afloramentos de rochas anortosíticas do Tocantins.

Intercaladas em rochas gabro-anortosíticas do Complexo do Tocantins, foram descritas, estudadas e analisadas pequenas lentes descontínuas de ilmeno-magnetita e magneto-ilmenita vanadíferas. Abstraindonse seu caráter econômico - ali irrelevante - e a despeito da ausência de estudos semelhantes em Barro Alto, elas servem de pontos de similaridades com o Complexo de Bushveld (África do Sul), onde igual ocorrência é registrada a cerca de 600 a $900 \mathrm{~m}$ abaixo do Merensky Reef.

Em uma única localidade, nas proximidades do contato ocidental da Zona do Topo do Complexo do Tocantins, caracterizou-se a presença de rocha com textura diabásica típica. O caráter único dessa amostra e sua ocorrência em dois locais ao longo da Zona Basal do Complexo de Barro Alto, em regiões afastadas de seus contatos orientais com encaixantes circunvizinhas, tornam prematura a suposição de que a referida rocha possa representar localmente o remanescente de uma possível fácies de resfriamento. Ademais, diques diabásicos de suposta idade cretácea, são observados nas proximidades de tais complexos, intrometidos quer em metassedimentos Araxá quer em pelitos e psamitos do Grupo Bambuí ou, ainda, em ambos.

Quimismo De acordo com Jackson (1967) dois métodos têm sido testados para se determinar o tipo de magma primário de intrusões básico-ultrabásicas, à semelhança de Stillwater, Bushveld e Great Dyke (Rodésia do Sul):

1) análises químicas das rochas das bordas;

2) somatório da composição química de todos os estratos diferenciados da intrusão.

A despeito de qualitativa e quantitativamente insuficientes, as análises químicas efetuadas em exemplares das respectivas Zonas Basais dos Complexos de Barro Alto e do Tocantins revelaram, em termos de percentagens de óxidos de elementos maiores, uma afinidade bastante notável. Tal analogia pôde ser igualmente estendida às porções basais de complexos estratiformes, à semelhança de Stillwater e Bushveld.

Do confronto de tais análises (Tab. I), onde, para efeito de comparação, registrou-se o resultado da análise química efetuada em um hiperstênio gabro de intrusão alpina típica e, apoiados em similaridades petrográficas, os autores admitem a possibilidade de que as respectivas Zonas Basais desses dois grandes complexos goianos, ou, quando menos, parte das mesmas, representem a margem oriental de tais intrusões, submetidas a um rápido resfriamento. 
Tabela I

\begin{tabular}{|c|c|c|c|c|c|c|}
\hline OXIDOS AMOSTRAS & $\mathrm{A}$ & $\mathrm{B}$ & 1 & 2 & 3 & 4 \\
\hline $\mathrm{SiO}_{2}$ & 50,5 & 49,6 & 50,68 & 48,08 & 51,00 & 47,69 \\
\hline $\mathrm{Al}_{2} \mathrm{O}_{3}$ & 16,3 & 18,8 & 17,64 & 17,22 & 16,95 & 16,75 \\
\hline $\mathrm{Fe}_{2} \mathrm{O}_{3}$ & 0,6 & 0,5 & 0,26 & 1,32 & 0,66 & 1,22 \\
\hline $\mathrm{FeO}_{\mathrm{CaO}}$ & 9,8 & 9,7 & 9,88 & 8,44 & 9,55 & 4,89 \\
\hline $\mathrm{MgO}^{2}$ & 9,9 & 11,7 & 10,47 & 11,38 & 11,12 & 15,27 \\
\hline $\mathrm{Na}_{2} \mathrm{O}$ & 7,6 & 7,2 & 7,71 & 8,62 & 7,57 & 11,12 \\
\hline $\mathrm{MiO}_{2}$ & 2,5 & 1,3 & 1,87 & 2,37 & 1,91 & 0,71 \\
\hline $\mathrm{K}_{2} \mathrm{O}$ & 1,0 & 0,3 & 0,45 & 1,17 & 0,50 & 0,17 \\
\hline $\mathrm{MmO}_{2}$ & 0,3 & 0,2 & 0,24 & 0,25 & 0,16 & 0,01 \\
\hline
\end{tabular}

(A) Hiperstênio gabro de granulação fina da zona basal do complexo de Barro Alto - análise pelo LAMIN (CPRM)

(B) Clinopiroxênio norito da zona basal do complexo do Tocantins - análise pelo LAMIN (CPRM)

(1) Hiperstênio dolerito* da zona de bordo resfriada de Stillwater - Anal. R. B. Ellestad (Hess, 1960 , in Wager e Brown, Tab. 26, 1968)

(2) Olivina gabro de resfriamento da intrusão de Skaergaard (in Wager e Brown, Tab. 26, 1968)

(3) Análise média de dois hiperstênio gabros de granulação fina da intrusão de Bushveld (in Wager e Brown, Tab. 26, 1968)

(4) Hiperstênio gabro do complexo de Canyon Moutain considerado tipo alpino (in Thayer e Himmelberg, Tab. I, 1968)

*O termo "dolerito" é aplicado nos Estados Unidos e na Alemanha como sinônimo de diabásio A ordem segundo a qual os elementos se encontram dispostos corresponde, aproximadamente àquela indicada por Taylor, R. S., como representativa da ocorrência média em basaltos (in Krauskopf, K. B., 1972)

Thayer (com. oral) refuta tal possibilidade, observando as grandes espessuras médias das Zonas Basais do Tocantins $(3 \mathrm{~km})$ e Barro Alto $(4,5 \mathrm{~km})$, quando comparadas, por exemplo, às margens de resfriamento de Stillwater e Bushveld, respectivamente $120 \mathrm{e}$ $160 \mathrm{~m}$. Interpreta aquelas zonas, como provenientes da crosta e arrastadas durante o emplacement dos peridotitos derivados do manto. Todavia, reciprocamente, e utilizando-se argumento similar, pode-se questionar tal interpretação atentando-se para as estreitas faixas de perídotitos observados em ambos os complexos - 1,5 km para Barro Alto e 2,7 km para o Tocantins. De que maneira, e sob quais circunstâncias (especificamente para Barro Alto, onde os contatos inferiores e superiores de sua Zona Ultrabásica são inquestionavelmente tectônicos), tal slice de ultrabásicas poderia ocasionar quando de seu posicionamento, o arrasto de 4,5 km de rochas gábricas, é ainda uma questão em aberto. Face ao exposto, não há como relegar as acentuadas analogias químicas e mineralógicas observadas entre partes das Zonas Basais desses complexos goianos e as respectivas margens resfriadas de Stillwater e Bushveld, em detrimento de teorias ainda bastante especulativas. 
Da Tab. II, deprende-se que a única discrepância significativa entre as percentagens em óxidos de elementos maiores do clinopiroxênio norito do Tocantins e do hiperstênio gabro de Barro Alto diz respeito ao teor mais elevado de alumina, exibido pelo primeiro. Hess (1938), verificando a mesma diferença entre rochas de resfriamento de Bushveld e Stillwater, e tendo em mente que tais intrusões ter-se-íam originado a partir de um mesmo tipo de magma, atribuiu tal diferença à profundidade de intrusão dos Complexos. Ele admite que, a maiores profundidades, o aumento de pressão favoreceria a entrada de alumina nas estruturas dos piroxênios. Jackson $(o p$. cit.) levanta dúvidas a respeito de tal raciocínio, chamando a atenção para o fato de que a amostra do hiperstênio dolerito da margem resfriada de Stillwater (amostra 1, Tab. 1), utilizada por Hess em sua comparação, seria duvidosamente representativa, pois análises mais recentes de três rochas consideradas de resfriamento do Complexo de Stillwater, acusaram variações nos teores de $\mathrm{Al}_{2} \mathrm{O}_{3}$ da ordem de 13 a $15 \%$. Challis (1965) questiona igualmente a hipótese de Hess e atribui as diferenças em alumina observadas em clinopiroxênios de rochas gábricas da intrusão de Red Hill (Nova Zelândia) como devidas ao controle químico, na dependência da disponibilidade de Si e Al.

Apesar de tais controvérsias, não pairam dúvidas quanto às afinidades magmáticas das intrusões que originaram esses dois complexos goianos e, a menos que estudos posteriores descartem a possibilidade de que pelo menos parte de suas Zonas Basais corresponde a membros resfriados, sugere-se a semelhança de Stillwater e Bushveld, um magma inicialmente basáltico e saturado, com alto conteúdo em alumina e afinidades toléticas, como fonte primária de tais intrusões.

Por problemas técnicos, os elementos-traços dos gabros basais de Barro Alto foram determinados apenas qualitativamente, porém, à semelhança dos exemplares basais do Tocantins (Tab. II), não apresentaram diferenças significativas. Em ambos, Ti e Mn são os principais elementos-traços, seguidos de $\mathrm{V}, \mathrm{Cu}, \mathrm{Ni}$, Co e $\mathrm{Cr}$.

Dados geocronológicos São conhecidos até o presente os resultados de vinte e cinco datações efetuadas pelo método $\mathrm{K}$-Ar, em rochas consideradas como pertencentes ao Complexo de Barro Alto (10) e do Tocantins (15).

Os exemplares de Barro Alto, de localizações conhecidas, foram analisadas pelo professor Adônis de Souza, da Universidade de Ribeirão Preto, SP, e revelaram idades aparentes, fortemente dispersas no intervalo 1 100-4000 m.a., supostamente atribuídas ao envolvimento do Complexo nos diversos ciclos tectônicos a que foi submetido. Embora o reduzido número de análises efetuadas e seus valores dispersos não permitam uma interpretação satisfatória, chama-se a atenção para o fato de as seis análises efetuadas, utilizando-se o anfibólio, que, segundo Hasui e Almeida (1970), têm fornecido resultados K-Ar dos melhores; duas delas caracterizaram as maiores cifras, absorvidas no intervalo 3800 -4030 m.a.

Das quinze datações a que foram submetidas rochas acreditadas pertencentes ao Complexo do Tocantins, desafortunadamente não se conhecem detalhes precisos de suas localizações. Motta et alii (op. cit.) lembram que, a despeito de Hasui e Almeida (op. cit.) referirem-se à cifra de $732 \pm 52$ m.a., obtidas para um hornblendito da Serra da Mantiqueira, nenhum membro do Projeto Niquelândia encontrou hornblendito em tal serra, após mapeamento em escala de 1:50 000. Outrossim treze outras datações efetuadas em gabros e noritos (termos vagos, considerando-se que tais rochas são igualmente comuns à Sequêencia Granulítica do Complexo Basal) procedentes de diversas, porém não-especificadas, zonas do Tocantins deram resultados igualmente dispersos, dessa feita no inter- 
Tabela II - Resultado de análises para elementos-traços de amostras da Zona Basal do Complexo do Tocantins

\begin{tabular}{|c|c|c|c|c|c|c|}
\hline $\begin{array}{l}\text { ELEMENTOS } \\
\text { MEAYORES }\end{array}$ & 2 & 2 & 3 & 4 & 5 & 6 \\
\hline Ti & 10.000 & 3.000 & 1.500 & 3.000 & 3.000 & 2.000 \\
\hline Mn & 5.000 & 6.000 & 1.000 & 1.500 & 1.500 & 1.500 \\
\hline$S x$ & $(-) 200$ & 200 & (-) 100 & $(-) 100$ & $(-) 100$ & $(-) 100$ \\
\hline $\mathrm{Ba}$ & 30 & 20 & - & - & - & - \\
\hline $\mathrm{V}$ & 200 & 200 & 150 & 150 & 500 & 300 \\
\hline $\mathrm{Cr}$ & 300 & 300 & 3.000 & $(+) 5.000$ & 3.000 & (t) 5.000 \\
\hline $2 r$ & 100 & 10 & - & - & - & - \\
\hline$M i$ & 70 & 85 & 300 & 2.000 & 300 & 500 \\
\hline $\mathrm{Cu}$ & 70 & 100 & 150 & 500 & 100 & 700 \\
\hline Co & 30 & 30 & 50 & 100 & 50 & 150 \\
\hline $\mathrm{Nb}$ & (m) 10 & $(-) 10$ & - & - & - & - \\
\hline $\mathrm{Pb}$ & 10 & (-) 10 & - & - & - & - \\
\hline Aล & $(-) 200$ & $(-) 200$ & - & - & - & - \\
\hline $\mathrm{Sn}$ & $(-) 10$ & $(-) 10$ & - & - & - & - \\
\hline Mo & $(-) 5$ & (m) 5 & - & - & - & - \\
\hline $\mathrm{Bi}$ & $(-) 10$ & $(-) 10$ & - & - & - & - \\
\hline AE & $(-) 0,5$ & $(-) 0,5$ & - & - & - & - \\
\hline$A u$ & $(-) 20$ & $(-) 20$ & ـ & - & - & - \\
\hline
\end{tabular}

Amostras: (1) clinopiroxênio-norito; (2) gabro alterado metamorficamente; (3) gabro piroxenítico cataclástico; (4) plagioclásio websterito; (5) hornblenda-hiperito; (6) Plagioclásio-hiperito

Laboratório responsável: LAMIN (CPRM)

Observąões: determinaçסes dos elementos por espectrografia semiquantitativa

Os valores tabulados acima referem-se a partes por milhão (P. P. M.)

O sinal negativo (-) indica que a concentração do elemento na amostra é inferior ao valor tabulado; contrariamente, o sinal $(+)$ indica que a concentração do elemento na amostra é superior ao valor tabulado

valo 700 a 3000 m.a., e foram apresentadas por Hasui et alii (1972) em resumo de comunicação ao XXVI Congresso Brasileiro de Geologia.

É digno de nota que, a despeito da sentida ausência de coordenação de trabalhos, os dados obtidos por meio de tais datações, reforçam a antiga suposição de uma idade pré-cambriana inferior para tais Complexos, a despeito de Thayer (com. oral) mostrar-se descrente de tais resultados, afirmando que idades de até $5000 \mathrm{~m}$.a. têm sido obtidas através do método K-Ar, para algumas das rochas do Complexo de Stillwater.

Conclusóes 1. Os Complexos de Barro Alto e do Tocantins apresentam similaridades em composição, estratigrafia, mineralogia, estrutura interna e associação mineral.

2. Evidências de campo, associadas a dados geocronológicos, apontam idade bem antiga para tais Complexos, supostamente pré-cambriana inferior; afasta-se a idéia de que os mesmos sejam co-magmáticos e de idades similares aos pequenos corpos de ultrabasitos alpinos, intrusivos, no Grupo Araxá (Serpentine Belt, de Almeida, 1967).

3. Por exibirem tanto feições alpinas quanto estratiformes, resistem às tradicionais classificações propostas e defendidas na literatura geológica mundial para caracterizar Complexos Básico-ultrabásicos.

Agradecimentos Os autores expressam seus agradecimentos ao geólogo Carlos Oiti Berbert, coordenador de recursos minerais da Agência Goiânia da GPRM, pelas críticas, sugestóes e cola* boração prestada. Agradecemos igualmente aos professores Fernando Flávio Marques de Almeida e José Moacir Vianna Coutinho pela revisão crítica do manuscrito e sugestões apresentadas. 


\section{BIBLIOGRAFIA}

ALMEIDA, F. F. M. de - 1967 - Observaçð̋es sobre o Pré-Cambriano da região central de Goiás. Bol. Paranaense de Geociências, 26, Curitiba, PR.: 19-22

ANGEIRAS, A. G. - 1968 - A faixa de serpentinitos da região central de Goiás. Inst. Geocièncias Univ. Federal do Rio de Janeiro, Rio de Janeiro, GB, An. Acad. Brasil. Giências, 40: 129-135

BAETA JR., J. D. A., FIGUEIREDO, A. N. et alii - 1972 - Projeto Goianésia-Barro Alto. Dep. Nac. Prod. Min., Cia. Pesq. Rec. Min., Rel, Final, Goiania, GO, v. 1, 129 pp.

BARbOSA, O. et alii - 1969 - Projeto Brasilia. Dep. Nac. Prod. Min., Prospec S/A, relatório inédito, Rio de Janeiro, $225 \mathrm{pp}$.

BERBERT, C. O. - 1970 - Geologia geral dos Complexos Básicos Ultrabásicos de Goiás. XXIV Congresso Brasileiro de Geologia, Brasília, DF, Soc. Bras. Geol., Bol. Especial n. ${ }^{\circ} 1,20$ pp.

CHALLIS, G. A. - 1965 - The origin of New Zealand ultramafic intrusions. Journal of Petrology, 6 (2): $322-364$

DA GOSTA, L. A. M. e ANGEIRAS, A. G. - 1971 - Geosynclinal evolution in the epi-Baykalian Platform of Central Brazil. Geol. Rundschau Bd. Stuttgart, 60 (2)

FLEISHER, R. e ROUTHIER, P. - 1970 - Quelques grands thèmes de la géologie du Brésil - Miscellanés géologiques et métallogéniques sur le Planalto. Sciences de la Terre, 15 (1): 45-102

HASUI, Y. e ALMEIDA, F. F. M. de - 1970 - Geocronologia do Centro-Oeste Brasileiro. Soc. Bras. Geol. B., São Paulo, SP, 19 (1): 5-26

HASUI, Y. et alii - 1972 - Idades Potássio-Argônio do Norte de Goiás. XXVI Cong. Bras. Geol., Belém, PA, Resum. Comum.

HESS, H. H. e PHILLIPIS, A. H. - 1938 - Ortopyroxenes of the Bushveld type. Am. Mineralogist, New York, 23: 450-456

JACKSON, E. - 1967 - Ultramafic cumulates in the Stillwater, Great Dyke and Bushveld intrusions. In: Wyllie, J. P., editor, Ultramafic and Related Rocks. New York, John Wyllie and Sons, pp. $20 \cdots 38$

KRAUSKOPF, K. B. - 1970 - Introdução à geoquímica. Trad. de M. Lando e P. S. C. Bogus - São Paulo, SP, Polígono - Univ. São Paulo, v. 2 pp. 232-234

LINDENMAYER, D. H. - 1970 - Relatório anual da Seção de Geologia e Mineralogia, Projeto Niquelândia, 6. ${ }^{\circ}$ Distrito, Centro-Oeste, Dep. Nac. Prod. Min., Relatório inédito, pp. 8-36

LINDENMAYER, Z. G. e LINDENMAYER, D. H. - 1971 - Rochas ultramáficas do Brasil central e suas mineralizaçóes a níquel. In: Congresso hispano-luso-americano de Geologia Econômica, $1 .{ }^{\circ}$, Madrid-Lisboa, pp. B-4-5

MOTTA, J. et alii - 1970 - Resumo das atividades do subprojeto Niquelândia. 6. Distrito Centro -Oeste, Dep. Nac. Prod. Min., Relatório inédito. Goiânia, GO, pp. 4 e 5

MOTTA, J. et alii - 1972 - Projeto Niquelândía. Dep. Nac. Prod. Min., Relatório final. Goiânia, GO, v. 1, 224 pp.

NILSON, A. A. - 1971 - Jazidas e Ocorrências de Amianto no Estado de Goiás. In: Gongresso hispano-luso-americano de Geologia Econômica, 1. ${ }^{\circ}$, Madrid-Lisboa, pp. B-4-6

PECORA, W. T. e BARBOSA, A. L. de M. - 1944 - Jazidas de níquel e cobalto do São José do Tocantins, Estado de Goiás. Div. Fom. Prod. Min., Bol. n. ${ }^{\circ} 64$, Rio de Janeiro, GB, 70 pp.

THAYER, T.P. - 1960 - Some critical differences between Alpyne-type and Stratiform Peridotite-Gabbro Complexes. Internat. Geol. Cong. XXI Session, Norden, Copenhagen 1960, pp. $247-259$

THAYER, T. P. - 1970 - Notes on the Geology and Resources of some Peridotites and Related Rocks in Brazil. U.S. Geol. Survey, Relat. inédito, BR-32, Washington D. C., n. ${ }^{\circ} 800$

WAGER, L. R. e BROWN, G. M. - 1968 - Layered Igneous Rocks. Edinburgh and London, Olliver and Boyd, $404 \mathrm{pp}$.

WHITE, R. - 1970 - Summary of my field activities in the Goiás Project. $6 .^{\circ}$ Distrito Centro-Oeste. Dep. Nac. Prod. Min., Relatório inédito, Goiânia, GO. pp. 2-4

WHITE, R. - 1970 - Variaçós na mineralogia da serpentina no "serpentine belt" de Goiás. XXIV Congresso Brasileiro de Geologia, Brasília, DF, Resum. Comun. pp. 301-304 